\title{
Bisphenol-A Release and Genotoxicity Differences of Three Lingual Retainer Adhesives Materials
}

\author{
Lydia Winarta', Rahmi Amtha², Boedi O. Roeslan ${ }^{3}$, Himawan Halim $^{1}$ \\ ${ }^{1}$ Postgraduate Program, Trisakti University, Jl. Kyai Tapa No.1, Jakarta, Indonesia \\ ${ }^{2}$ Department of Oral Medicine, Trisakti University, Jl. Kyai Tapa No.1, Jakarta, Indonesia \\ ${ }^{3}$ Department of Biochemistry, Trisakti University, Jl. Kyai Tapa No.1, Jakarta, Indonesia \\ ${ }^{4}$ Department of Orthodontics, Trisakti University, Jl. Kyai Tapa No.1, Jakarta, Indonesia \\ Correspondencee-mail to: lydia_oey@yahoo.com
}

\begin{abstract}
Objectives: The objective of the study were to determine if there was any (bisphenol A) BPA release from three adhesive brands, to determine the differences of BPA release between three adhesive brands, to determine the genotoxicity from three adhesive brands, and to determine the correlation of BPA release and genotoxicity. Methods: Three branded adhesives materials were polimerized in mold and immersed in $\mathrm{pH} 7$ and 4 artificial saliva from 24 to 720 hours. The artificial saliva was tested with spectrophotometry test to see BPA release at 24, 240, 480, and 720 hours, then freeze dried to get solid extract. Combination of the extract and lymphocite culture (male and female) then tested with in vitro cytokinesis-block micronucleus (MN) assay to see genotoxicity level of three adhesives at 24, 240, 480, and 720 hours as well. Results: The BPA release occured at 720 hours by Adhesive 1: $0.013 \mu \mathrm{g} / \mathrm{L}$; Adhesive 2: $0.11 \mu \mathrm{g} / \mathrm{L}$; Adhesive 3: $0.036 \mu \mathrm{g} / \mathrm{L}$. There was a statistically significant difference between BPA release with time $(F=505.98 ; p=0.00)$ and brands $(F=147.65 ; p=0.00)$. Time and BPA release interaction also showed a statistically significant difference $(\mathrm{F}=13.35 ; \mathrm{p}=0.00)$. Genotoxicity can be seen at 720 hours on Flowtain LV sample (MN frequency: male: 0.044; female: 0.053). Conclusion: The number of BPA release of all brand can be seen from the first 24 hours, and were increasing from 24 to 720 hours. Genotoxicity can be seen from one of the adhesive brand at 720 hours. There was correlation between BPA leaching and micronucleus frequency.
\end{abstract}

Keywords: BPA, spectrophotometry, micronucleus test

\section{INTRODUCTION}

A lingual retainer is used to maintain tooth position post orthodontic treatment. It is bonded to the lingual side of anterior teeth using composite. Various composites have been described for use in this technique including both restorative and orthodontic bonding materials. Various restorative and orthodontic bonding materials have been used as lingual retainer materials. The flowable composites as bonding for lingual retainers are increasingly used. Several studies have tested the shear bond strength (SBS) of Filtek Supreme and Tetric Flow. ${ }^{1}$ The SBS values for Filtek Supreme, and Tetric Flow were $22.4 \pm 16.3$, and $16.8 \pm 11.8 \mathrm{MPa}$, respectively, and mean pullout values were $26.3 \pm 9.4$, and $33.8 \pm 18.0$ $\mathrm{N}$, respectively. These flowable composites provided satisfactory SBS and wire pullout values, comparable to a standard orthodontic resin. Therefore, they can be used as an alternative for direct bonding of lingual retainers. ${ }^{1}$

Bisphenol A (BPA) is a synthetic chemical with known disruptive endocrine and weak estrogenic properties. ${ }^{16}$ lobal attention to its use as an environmental contaminant to human health is increasing. A great exposure to BPA could have an impact on endocrine-disrupting properties in human. ${ }^{2}$ In clinical dentistry, BPA is a precursor of the bisphenol A glycidyl methacrylate (bis-GMA), bisphenol-A di-methacrylate (bis-DMA), and bisphenol A ethoxylated di-methacrylate (bis- 
EMA) monomers found in dental sealants, adhesive resins, and composite resins. The degradation of these materials can leach BPA into the oral environment. This could be a clinical concern and could be exacerbated by temperature changes, mechanical wear, changes in $\mathrm{pH}$, and bacterial or salivary enzymatic action. ${ }^{3}$

Micronuclei $(\mathrm{MN})$ are the structures that arise from acentric chromosome fragments or complete chromosomes that failed to attach to mitotic spindle during cytokinesis. These structures are excluded from the daughter nuclei into the cytoplasm. ${ }^{4}$ Micronucleus is the target structure for the toxicological screening to explore potential genotoxicity of a material. The in vitro chromosomal aberration potential of a material could be done using cytokinesis-block assay. ${ }^{5}$

The adhesive materials used in conservative dentistry such as Filtek Supreme and Tetric N-Flow have been tested in vitro that it can be used as well as lingual retainer adhesive. The other type called Flowtain $\mathrm{LV}$ is an adhesive material with lingual retainer attachment purpose. However there is no report of the BPA release of those three adhesive materials has been reported. Therefore, there are four purposes of this study. Firstly, to determine if there was any BPA release from three adhesives brands. Secondly, to determine the differences of BPA release between three adhesive brands. Thirdly, to determine the genotoxicity from three adhesive brands. Lastly, to determine the correlation of BPA release and genotoxicity.

\section{METHODS}

This research type is experimental laboratory (in vitro) with post-treatment randomized controlled trial design to determine the BPA release and the genotoxicity of three adhesive brands, which simulated by immersing adhesives in artificial saliva with specified $\mathrm{pH}$ in four different testing time.

A range of materials contains bis-GMA and bis-EMA was selected for use in this study (Table 1). They are identified as Adhesive 1, Adhesive 2; both are restorative flow composites, and a lingual retainer bonding Adhesive 3, were used. The weight of material used is determined by attaching lingual retainer on tooth model. Then those adhesives were cured for 20 seconds in cylindrical form with $1 \mathrm{~mm}$ height. Three samples from each adhesive then immersed in artificial saliva at pH4 and pH 7 due to Stephan curves. Saliva samples were collected after immersed at 24, 240, 480, and 720 hours, and mixed between $\mathrm{pH} 4$ and $\mathrm{pH}$ 7. BPA release was measured with spectrophotometry assay by using pure BPA (Sigma, Buchs, Switzerland) that mixed with artificial saliva. It was performed by using BioDrop $\mu$ Lite (Figure 1), in triplicate for each sample per time period, and the results were averaged.
Table 1. Ingredients of three adhesives materialsused for lingual retainer attatchment. ${ }^{6,7,8}$

\begin{tabular}{|c|c|c|}
\hline Adhesive & Ingredients & $\begin{array}{l}\text { \% by } \\
\text { weight }\end{array}$ \\
\hline 1 & $\begin{array}{l}\text { Bisphenol A diglycidyl ether } \\
\text { dimethacrylate (Bis-GMA) }\end{array}$ & $<40$ \\
\hline 2 & $\begin{array}{l}\text { - Silane treated ceramic } \\
\text { - Silane treated silica } \\
\text { - UDMA } \\
\text { - } \text { diethener dimethacrylate (Bis-EMA) } \\
\text { - Bisphenol A diglycidyl ether } \\
\text { dimethacrylate (Bis-GMA) } \\
\text { - Silane treated zirconia } \\
\text { - Polyethilene glycol dimethacrylate } \\
\text { - TEGDMA } \\
\text { - 2,6-di-tert-butyl-p-cresol }\end{array}$ & $\begin{array}{l}60-80 \\
1-10 \\
1-10 \\
1-10 \\
\\
1-10 \\
1-10 \\
<5 \\
<5 \\
<0,5\end{array}$ \\
\hline 3 & $\begin{array}{l}\text { - ethoxylated bisphenol } \\
\text { A dimethacrylate } \\
\text { - glass filler } \\
\text { - TEGDMA }\end{array}$ & $\begin{array}{l}>10 \\
>50 \\
<15\end{array}$ \\
\hline
\end{tabular}

A standard curve was made to decide the wavelength that will be used to measure BPA release for the samples. The wavelength used was $285 \mathrm{~nm}(\mathrm{R} 2=$ $0.968)$. Samples were pipetted $0.5 \mu \mathrm{L}$ in the center of BioDrop $\mu$ Lite port and measure. The port needs to wipe with a lint-free tissue before the next measurement.

The samples were freeze-dried to get the solid extract of artificial saliva, before the genotoxicity test. The freeze drying will prevent the contamination during culture test. Freeze-drying was performed for 16 hours (Figure 2).

Micronucleus test was carried out to detect genotoxicity of the three adhesive materials in human using peripheral blood lymphocyte culture. Blood sample was collected $4 \mathrm{~mL}$ from healthy male and female donors. On the culture tube $4.5 \mathrm{~mL}$ RPMI (Roswell Park Memorial Institute, Gibco), $1 \mathrm{~mL}$ FBS (Fetal Bovine Serum, Gibco), $0.2 \mathrm{~mL}$ Pen-Strep (Penicilin-Streptomycin, Sigma), 0.2 mL PHA (Phytohemaglutinin, Sigma), and freeze-dried adhesive extract were added. Then blood tubes were incubated at 5\% $\mathrm{CO} 2$ atmosphere, a tempertature of $37^{\circ} \mathrm{C}$, until the time of Cytochalasin-B (cythochalasin-B, Sigma) addition (44 hours after PHA additon) in order to stop division of cells. Blood cultures that were not given any adhesive extract used as control. The culture process ended at 68-72 hours after PHA addition. Blood culture then centrifugated at $800 \mathrm{rpm}$ for 10 minutes, and the supernatant was discarded. The hypotonic solution, $0,075 \mathrm{M} \mathrm{KCl}$, was added and centrifugated immediately at $800 \mathrm{rpm}$ for 8 mins. Supernatant was discarded and the fixative solution was added. Repeat the centrifugation at 800 rpm for 8 minutes lymphocytes washed 2-3 times with fixative solution until clear cell suspensions are obtained. Supernatant removed and cell plate would stay at approximately $1 \mathrm{~cm}$ on the bottom of the tube. 


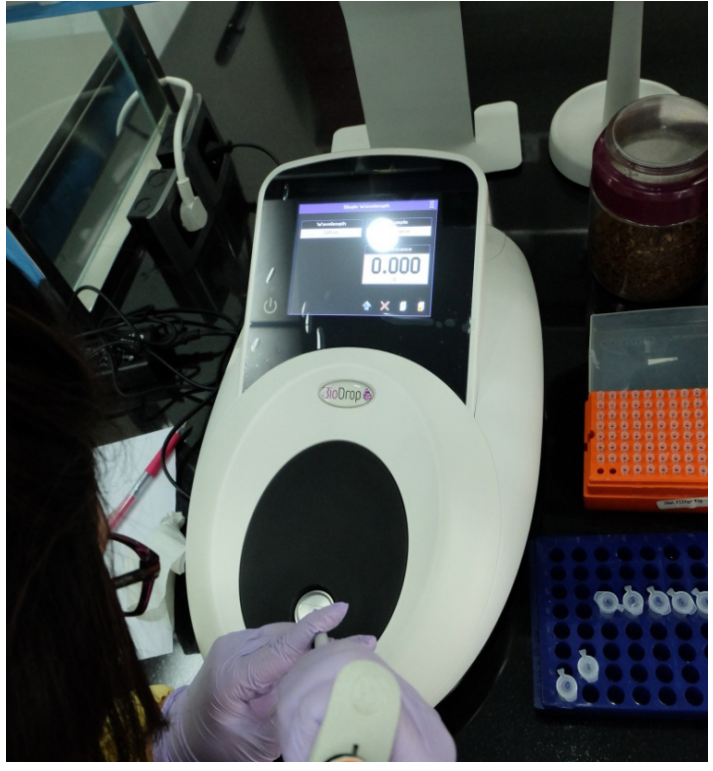

Figure 1. BioDrop $\mu$ LITE to measure BPA release.

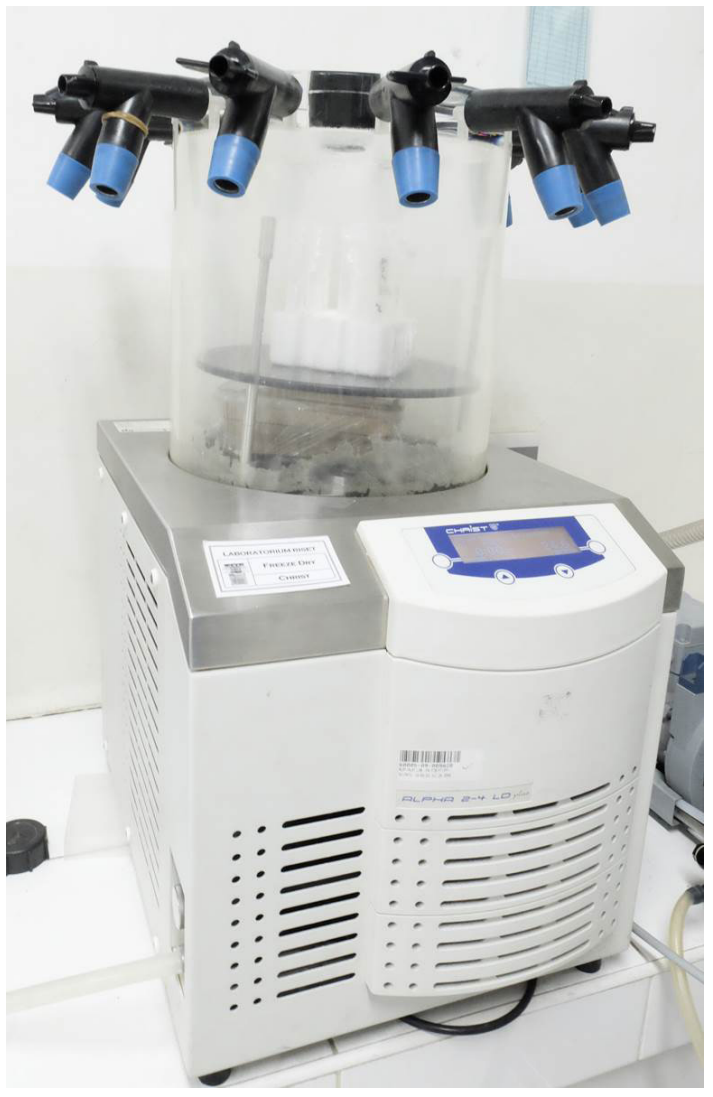

Figure 2. Freeze dry machine, Christ, Alpha 2-4 plus

The cell then dropped on glass objects. At the end of the test, microscopic sections were preserved and dyed with the use of the Giemsa staining method. The results were seen under a light microscope showed cytoplasm turns light blue and the nucleus violet-pink. The result of the test is the percentage of binucleated cells with micronuclei-to-binucleated cells without micronuclei (in a pool of 1000 cells).
Table 2. The average number of BPA release from three adhesives after immersion in artificial saliva

\begin{tabular}{cccc}
\hline $\begin{array}{c}\text { Time } \\
\text { (hours) }\end{array}$ & $\begin{array}{c}\text { Adhesive 1 } \\
(\boldsymbol{\mu g} / \mathbf{L}) \\
(\boldsymbol{S D}= \\
\mathbf{0 . 0 0 4 )}\end{array}$ & $\begin{array}{c}\text { Adhesive 2 } \\
(\boldsymbol{\mu g} / \mathbf{L}) \\
(\boldsymbol{S D}= \\
\mathbf{0 . 0 0 3 )}\end{array}$ & $\begin{array}{c}\text { Adhesive 3 } \\
(\boldsymbol{\mu g} / \mathbf{L}) \\
(\boldsymbol{S D}=\mathbf{0 . 0 1 6})\end{array}$ \\
\hline 24 & 0.005 & 0.004 & 0.001 \\
240 & 0.006 & 0.006 & 0.004 \\
480 & 0.010 & 0.009 & 0.015 \\
720 & 0.013 & 0.011 & 0.036 \\
\hline
\end{tabular}

Table 3. Micronucleus frequencies on lymphosites culture from three adhesives

\begin{tabular}{lccccccc}
\hline \multirow{2}{*}{$\begin{array}{c}\text { Time } \\
\text { (hour) }\end{array}$} & \multicolumn{2}{c}{ Adhesive 1 } & \multicolumn{2}{c}{ Adhesive 2 } & \multicolumn{2}{c}{ Adhesive 3 } \\
\cline { 2 - 8 } & $\begin{array}{c}\text { Male } \\
(\boldsymbol{S D}=\end{array}$ & $\begin{array}{c}\text { Female } \\
(\boldsymbol{S D}=\end{array}$ & $\begin{array}{c}\text { Male } \\
(\boldsymbol{S D}=\end{array}$ & $\begin{array}{c}\text { Female } \\
(\boldsymbol{S D}=\end{array}$ & $\begin{array}{c}\text { Male } \\
(\boldsymbol{S D}=\end{array}$ & $\begin{array}{c}\text { Female } \\
(\boldsymbol{S D}=\end{array}$ \\
\hline 24 & 0.021 & 0.028 & 0.018 & 0.026 & 0.014 & 0.026 \\
240 & 0.025 & 0.031 & 0.024 & 0.028 & 0.024 & 0.027 \\
480 & 0.026 & 0.034 & 0.026 & 0.030 & 0.030 & 0.037 \\
720 & 0.030 & 0.037 & 0.028 & 0.036 & 0.044 & 0.053 \\
\hline
\end{tabular}

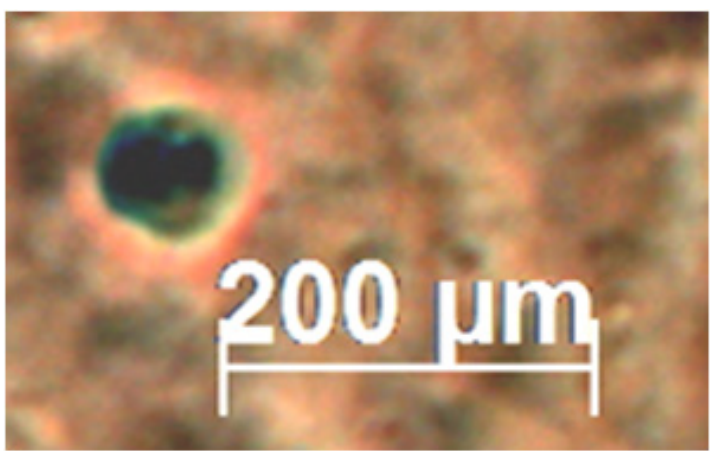

Figure 3. Binucleus cell seen with light microscope

The correlation between BPA release and MN frequency tested with Pearson test. There is correlation between BPA release and MN frequency with a value of $0.859(\mathrm{p}=0)$.

The data was analyzed using Kolmogorov-Smirnov normality test. The data then analyzed descriptively, and then hypothesis verification performed with twoway ANOVA to examine the significance of BPA release, followed by multiple comparisons test Honestly Significant Difference (HSD) Tukey and one-way ANOVA to determine intragroup differences. Pearson test was done to see the correlation between BPA release and $\mathrm{MN}$ frequency.

\section{RESULTS}

The result of Kolmogorov-Smirnov test indicates that all data groups have a normal distribution $(\mathrm{p}>0.05)$. The result of BPA release test using BioDrop at $285 \mathrm{~nm}$ 
waves length can be seen in Table 2. The data between three samples from each brand were averaged The table showed an increasing number of BPA release from 24 to 720 hours. Adhesive 2 had the lowest BPA release, and the highest was Adhesive 3.

Statistical analysis of BPA release by using two-way ANOVA showed a statistical difference between BPA release with time $(\mathrm{F}=505.98 ; \mathrm{p}=0)$ and brands $(\mathrm{F}=147.65 ; \mathrm{p}=0)$. Statistical analysis then continued with one-way ANOVA and HSD Tukey. One way ANOVA showed a difference between BPA release and time $(F=13.35 ; p=0)$, and no difference between BPA release and brands $(F=2 ; p=0.151)$. HSD Tukey showed there were differences between time 1 and 3 , 2 and 4,3 and 4.

The result of MN frequency can be seen in Table 3. Micronucleus frequency was increasing from 24 hours to 720 hours. The highest MN frequency saw from adhesive 3. Average female's MN frequency was higher than male.

\section{DISCUSSION}

The results of the BPA content of the immersion media are shown in Table 2. BPA was released at measurable amounts since the first 24 hours, whereas the highest concentration was observed for the 720 hours group. In contrast, analysis of the immersion media before bonding, which was used as a control, was $0.001 \mu \mathrm{g} / \mathrm{L}$. These results show the same pattern with the research done previously. ${ }^{1}$ on the BPA leaching that indicates average release of BPA reached the highest number at 720 hours. ${ }^{9}$ This may be due to the accumulative immersion used.

Adhesive 3 shows the highest amount of BPA release, whereas adhesive 2 was the lowest. Based on adhesives' MSDS (Material Safety Data Sheet); there are BisGMA on Adhesive 1, Bis-GMA and Bis-EMA on Adhesive 2, and Bis-EMA on Adhesive 3. Compare with bis-GMA, bis-EMA absorb less water. Along with Sideridou's study of water sorption, solubility and modulus of elasticity of light-cured di-methacrylatebased dental resins, Bis-EMA create more rigid physical properties networks, which absorb less water and release higher unreacted monomer. The mixture of bis-GMA and bis-EMA in adhesive 2 forms a more flexible networks (lower Young's modulus) than bisGMA itself, it has less water absorption and the least unreacted monomer release. ${ }^{10}$

The United States and the European Food Safety Authority's stated the human exposure tolerable limit of BPA daily intake is $50 \mathrm{mg}$ per kilogram per day. The BPA released from the adhesive materials in this study was far below the doses, and it can be concluded to be a safe treatment method at present. There are some controversies regarding the safe level of BPA exposure. Other study found that a BPA level far below $50 \mathrm{mg}$ can cause biologic functions changes in vitro and in vivo, even part-per-trillion doses of BPA can alter cell functions and might elicit changes in cellular level signaling. ${ }^{11}$ This value is lower than the figure observed in laboratory conditions of this study, which certainly underestimates the full potential of BPA release in actual conditions and for extended periods of time. ${ }^{9}$

Micronucleus frequency can be seen from the first 24 hours, then increasing to 720 hours. There was genotoxic activity from Adhesive 3 at 720 hours on both male and female. Micronucleus frequency in female was higher than male. It also coincides with the micronucleus test done in previous studies. ${ }^{12,13}$ Difference frequencies micronuclei between male and female is likely due to higher susceptibility to mal segregation of chromosome $\mathrm{X}$ in comparison with autosome and distal lagging behind in anaphase. Chromosome $\mathrm{X}$ sensitivity to aneuploidy was suggested to be due to premature centromere division and modified centromere function. ${ }^{12,13}$ It has to be considered that adhesive used in this study also contain other composition that got toxic potential as TEGDMA (tri-ethylene glycol di-methacrylate). TEGDMA is one of the monomers used to thinned bis-GMA to achieve a suitable viscosity. So genotoxic activity may not only caused by BPA.

\section{CONCLUSION}

From the research above, it can be concluded that BPA release can be seen from each brand. The number of BPA release of all brand was increasing from 24 to 720 hours. Adehesive 3 released the highest number of BPA, however the BPA release did not influence by brands. Genotoxicity can be seen from Adhesive 3 at 720 hours. There was a correlation between BPA leaching and micronucleus frequency.

\section{REFERENCES}

1. Tabrizi S, Salemis E, Usumez S. Flowable composites for bonding orthodontic retainers. Angle Orthod. 2010; 80:196-200.

2. Fujimoto V, Kim D, Saal FV, Lamb JD, Taylor JA, Bloom MS. Serum unconjugated bisphenol A concentrations in women may adversely influence oocyte quality during in vitro fertilization. Fertil Steril. 2011; 96:1816-9.

3. Kotyk M, Wiltshire W. An ivestigation into bisphenol-A leaching from orthodontic materials. Angle Orthod. 2014; 84: 516-20.

4. Slowinski J, Bierzynska-Macyszyn G, Mazurek U, Widel M, Latocha M, et al. Cytokinesis-block 
micronucleus assay in human glioma cells exposed to radiation. Anal Stereol. 2004; 23:158-65.

5. Diaz D, Scott A, Carmichael P, Shi W, Costales C. Evaluation of an automated in vitro micronucleus assay in HO-k1 cells. Mutat Res. 2007; 630:1-13.

6. 3M. Material safety data sheet $6029 \mathrm{M}$ 3M ${ }^{\text {TM}}$ ESPETMFILTEK ${ }^{\text {TM }}$ SUPREME ULTRA universal restorative master kit; 2009.

7. Reliance. Material safety data sheet. Flowtain LV. 2009.

8. Vivadent I. EU Safety Data Sheet Tetric N-Flow; 2007.

9. Eliades T, Voutsa D, Sifakakis I, Makou M, Katsaros C. Release of bisphenol-A from a lightcured adhesive bonded to lingual fixed retainers. Am J Orthod Dentofac Orthop. 2011;139:192-5.
10. Sideridou I, Tserki V, dan Papanastasiou G. Study of water sorption, solubility and modulus of elasticity of light-cured dimethacrylate-based dental resins. Biomaterials. 2003; 24: 655-65.

11. Kang Y, Kim J, Kim J, Won P, Nam J. Release of Bisphenol A from resin composite used to bond orthodontic lingual retainers. Am J Orthod Dentofac Orthop. 2011; 140:779-89.

12. Wodja A, Zietkiewicz E, dan Witt M. Effects of age and gender on micronucleus and chromosome nondisjunction frequencies in centenarians and younger subjects. Mutagenesis. 2007; 22:195-200.

13. de Araujo TK, da Silva-Grecco RL, Bissinotto FMB, Rosso NC, Pissetti CW, et al. Genotoxic effects of anesthetics in operating room personnel evaluated by micronucleus test. J Anesthesiol Clin Sci. 2013; 2:26.

(Received July 1, 2015; Accepted December 8, 2015) 